\title{
Correction to: A novel method of grading gastric intestinal metaplasia based on the combination of subtype and distribution
}

Ning Wei ${ }^{1,2} \mathbb{C}$, Zhiheng Zhong ${ }^{1,2}$ and Ruihua Shi ${ }^{1,2^{*}}$

\section{Correction to: Cancer Cell Int (2021) 21:61} https://doi.org/10.1186/s12935-021-01758-6

Following publication of the original article [1], we were notified that the corresponding author has been incorrectly flagged. The correspondence has been modified.

The original article has been corrected.

\section{Author details}

${ }^{1}$ Medical School of Southeast University, No. 87 Dingjiagiao, Nanjing 210009,

China. ${ }^{2}$ Department of Gastroenterology, Southeast University Affiliated

Zhongda Hospital, No. 87 Dingjiaqiao, Nanjing 210009, China.

Published online: 24 February 2021
Reference

1. Wei N, Zhong Z, Shi R. A novel method of grading gastric intestinal metaplasia based on the combination of subtype and distribution. Cancer Cell Int. 2021;21:61. https://doi.org/10.1186/s12935-021-01758-6.

\section{Publisher's Note}

Springer Nature remains neutral with regard to jurisdictional claims in published maps and institutional affiliations. 